\title{
A Comparative Study of Corneal Endothelial Cell Count and Central Corneal Thickness in Emmetropia and Axial Myopia
}

\author{
Vandana Panjwani ${ }^{1}$, Sachin Daigavane ${ }^{2}$ \\ 1,2 Department of Ophthalmology, Jawaharlal Nehru Medical College, Datta Meghe Institute of Medical \\ Sciences (Deemed University), Sawangi (Meghe), Wardha, Maharashtra, India.
}

\section{ABSTRACT}

\section{BACKGROUND}

The main attributes of cornea which makes it optically important is its ability to maintain its dehydrated state. This corneal dehydration can be achieved and maintained by various factors among which corneal endothelial cell count and morphology play a significant role. Corneal attributes considered in this study i.e. the corneal endothelial cell count and central corneal thickness are extremely variable, and changes are seen even with smaller changes in anterior segment or overall structural changes in eyes. We wanted to compare central corneal thickness in emmetropia and axial myopia and compare corneal endothelial cell count in emmetropia and axial myopia.

\section{METHODS}

The sample size was decided taking into consideration various prevalence studies. The patients were consecutively recruited for the study considering the inclusion and exclusion criteria. The subjects were divided into two groups emmetropia and axial myopia and were differentiated on the basis of the axial lengths. Specular microscopy was performed for the subjects and corneal endothelial cell count, morphology and central corneal thickness were measured, and comparative study was performed.

\section{RESULTS}

This study of 80 eyes shows us that the difference between mean the corneal endothelial cell count between emmetrope (2812.80 cells $/ \mathrm{mm}^{2}$ ) and axial myopes ( 2653 cells $/ \mathrm{mm}^{2}$ ) is statistically significant where $\mathrm{p}$ was $<0.05$ while the mean central corneal thickness measurements didn't show statistically significant change between emmetrope (490.05 microns) and axial myope. (489.37 microns).

\section{CONCLUSIONS}

Axial length has an indirect correlation with the corneal endothelial cell count which is statistically significant. While significant correlation between the central corneal thickness and axial length cannot be established in this study.

\section{KEY WORDS}

Emmetropia, Axial Myopia, Corneal Endothelial Cell Count, Central Corneal Thickness, Comparison
Corresponding Author: Dr. Vandana Panjwani, S - 19 Shalinata PG Girls Hostel, Datta Meghe, Institute of Medical Sciences (Deemed University), Sawangi (Meghe), Wardha, Maharashtra, India. E-mail: vandanapanjwani11@gmail.com

DOI: $10.14260 /$ jemds/2020/725

How to Cite This Article:

Panjwani V, Daigavane S. A comparative study of corneal endothelial cell count and central corneal thickness in emmetropia and axial myopia. J Evolution Med Dent Sci 2020;9(44):3300-3304, 10.14260/jemds/2020/725

Submission 29-05-2020,

Peer Review 23-09-2020,

Acceptance 30-09-2020,

Published 02-11-2020.

Copyright (C) 2020 Vandana Panjwani et al. This is an open access article distributed under Creative Commons Attribution License [Attribution 4.0 International (CC BY 4.0)] 


\section{BACKGROUND}

Axial myopia is a result of an elongated eyeball. A $1 \mathrm{~mm}$ elongation produces approximately $3 \mathrm{D}$ of myopia. ${ }^{1}$ Emmetropic eyes may differ in length by as much as $1-2$ $\mathrm{mm}$. Therefore, Normal axial length: $22-24 \mathrm{~mm}$. The cornea serves as the principal refractive element in the eye. There are certain attributes of the cornea which makes it an optically significant part of the eye. Some of these attributes are corneal endothelial cell count and morphology and corneal thickness.

\section{Rationale}

In clinical practice we come across many a patients with axial myopia and while we know the difference of visual acuity and best corrected visual acuity, it might be interesting to know the difference in certain corneal attributes which in turn modifies the ultimate diagnosis, prognosis and therapeutic overview in patients with axial myopia.

So, to state, CCT and corneal endothelial cell count plays an important role in diagnosing certain conditions, and their management also depends upon the endothelial cell count and morphology.

And axial myopia being a relatively common ocular pathology with good symptomatic relief with appropriate refractive correction, other anterior segment and corneal attributes might be overlooked which later can lead to inevitable complications as a result of axial myopia.

We wanted to compare corneal endothelial cell count and central corneal thickness in emmetropia and axial myopia.

\section{METHODS}

This is a hospital based comparative cross-sectional study conducted in the Department of Ophthalmology, Acharya Vinoba Bhave Rural Hospital, Sawangi, over a period of 6 months from April 2019 to October 2019, among patients in the age group of 15 - 49 years, coming to ophthalmology OPD at AVBRH. All the patients with pterygiums, ${ }^{2}$ corneal pathologies, $\mathrm{h} / \mathrm{o}$ any previous trauma to the eye, any previous operative procedure in the eye, raised intraocular pressure $^{3}$ and know case of diabetes were excluded from the study

\section{Sample Size}

Sample size of the following study is 80 eyes of 40 subjects divided into two groups emmetropia group and axial myopia group with 40 eyes of 20 subjects in each group, with keeping in consideration the incidence of axial myopia in the study setup in the duration of 6 months.

\section{Data Collection Tools and Process}

The study adheres to the tenets of Declaration of Helsinki and was finalised by the ethical committee of our institution.

The subjects attending the ophthalmological OPD were screened and selected consecutively for the study after taking the inclusion and exclusion criteria into the consideration.
Visual acuity was measured for the patients using Snellen's visual acuity chart.4,5 Unaided visual acuity, visual acuity with pinhole and best corrected visual acuity, all the three were recorded in order to carefully select the subjects.

Following this, Torch light examination, slit amp examination, intraocular pressure using goldmann applanation tonometer ${ }^{6}$ and random blood sugar levels were done for the subjects.

After thorough anterior segment examination, contact A scan biometry was done to determine the axial lenght of the subject, it was done by a single technician by a single method to avoid any bias.

Then depending upon the visual acuity, complete anterior segment examination and evaluation of the axial length the subjects were divided into two gropus of emmetropia and axial myopia.

Subjects with axial length more than $24 \mathrm{~mm}$ were grouped as axial myopia and those with axial length between $21-24$ $\mathrm{mm}$ were grouped as emmetropia. Later on, Specular microscopy was performed to evaluate the central corneal thickness and endothelial cell count and percentage of hexagonality. Topcon SP-1P non contact specular microscope was used by a single examiner.

Findings were read and comparative observations were made accordingly, again it was done by a single observer in order to avoid the observer bias

\section{Statistical Analysis}

Statistical analysis was done by using descriptive and inferential statistics using chi-square test, student's unpaired t test and Pearson's Correlation coefficient and software used in the analysis were SPSS 24.0 version and GraphPad Prism 7.0 version and $p<0.05$ is considered as level of significance.

\section{RESULTS}

The study was done in the Department of Ophthalmology of a tertiary care center from May 2019 to October 2019. This study included 40 patients, out of which 20 subjects were emmetropic and 20 subjects had axial myopia. Visual acuity, axial length, central corneal thickness, corneal endothelial cell count and corneal endothelial cell morphology were evaluated in this study and correlation between them was studied.

The age of diagnosis plays an important role in deciding the management of the axial myopia. More commonly the patients are diagnosed in young age.

In our study, the maximum number of patients in axial myopic group and emmetropic group were in the age group of 35 - 44 years. The least number of patients in axial myopia and emmetropia group were in the age group of 15 - 24 years.

The sexual predominance of the condition in not known exactly, although males present commonly because females tend to realize the vision loss less frequently as they are mostly confined to household work.

In the study conducted here, out of 20 patients of axial myopia patients, $60 \%$ were males and $40 \%$ were females and out of 20 patients of emmetropia $45 \%$ patients were males and $55 \%$ were females. 
As discussed earlier, patients having axial length of $>24$ $\mathrm{mm}$ is considered to have axial myopia.

Here, the mean axial length in the patients in axial myopia group was $24.79 \pm 1.03$ with standard mean error of 0.16 and the mean axial length in emmetropia group was $22.39 \pm 0.47$ with standard mean error of 0.07 .

\begin{tabular}{|cccc|}
\hline & Axial Myopia & Emmetropia & $\chi 2$-Value \\
$15-24$ yrs & $8(40 \%)$ & $9(45 \%)$ & \\
$25-34$ yrs & $3(15 \%)$ & $4(20 \%)$ & 6.83 \\
$35-44$ yrs & $4(20 \%)$ & $4(20 \%)$ & $\mathrm{P}=0.077, \mathrm{NS}$ \\
$\geq 45$ yrs & $5(25 \%)$ & $3(15 \%)$ & \\
Total & $\mathbf{2 0}(\mathbf{1 0 0} \%)$ & $\mathbf{2 0}(100 \%)$ & \\
Mean & $35.65 \pm 10.10$ & $35.70 \pm 6.89$ & \\
\hline \multicolumn{4}{r}{ Table 1. Distribution of Patients in to Two Groups According to Age } \\
\hline
\end{tabular}

\begin{tabular}{|cccc|}
\hline Gender & Axial Myopia & Emmetropia & $\chi 2-$ Value \\
Male & $12(60 \%)$ & $9(45 \%)$ & 10.11 \\
Female & $8(40 \%)$ & $11(55 \%)$ & $\mathrm{P}=0.0001, \mathrm{~S}$ \\
Total & $\mathbf{2 0}(\mathbf{1 0 0} \%)$ & $\mathbf{2 0}(\mathbf{1 0 0} \%)$ & \\
\hline Table 2. Distribution of Patients in to Two Groups According to Gender \\
\hline
\end{tabular}

\begin{tabular}{|cccccc|}
\hline & N & Mean & Std. Deviation & Std. Error Mean & t-Value \\
Axial Myopia & 40 & 24.79 & 1.03 & 0.16 & 13.36 \\
Emmetropia & 40 & 22.39 & 0.47 & 0.07 & $\mathrm{P}=$ \\
& \multicolumn{5}{|c}{ Table 3. Comparison of Axial Length in the Two Groups } \\
Student's Unpaired t Test & $0.0001, \mathrm{~S}$ \\
\hline \multicolumn{5}{|c|}{} \\
\hline
\end{tabular}

\begin{tabular}{|cccccc|}
\hline & N & Mean & Std. Deviation & Std. Error Mean & t-Value \\
Axial myopia & 40 & 2653 & 340.99 & 53.91 & 2.13 \\
Emmetropia & 40 & 2812.80 & 329.005 & 52.02 & $\mathrm{P}=$ \\
\hline Table 4. Comparison of Endothelial Cell Count in the Two Groups \\
Student's Unpaired t Test \\
\hline
\end{tabular}

\begin{tabular}{|cccccc|}
\hline & N & Mean & Std. Deviation & Std. Error Mean & t-Value \\
Axial Myopia & 40 & 489.37 & 24.47 & 3.86 & 0.15 \\
Emmetropia & 40 & 490.05 & 13.21 & 2.08 & $\mathrm{P}=$ \\
\hline \multicolumn{5}{|c|}{ Table 5. Comparison of Central Corneal Thickness in the } \\
Two Groups Student's Unpaired t Test
\end{tabular}

\begin{tabular}{|cccccc|}
\hline & Mean & $\begin{array}{c}\text { Std. } \\
\text { Deviation }\end{array}$ & N & Correlation & $\begin{array}{c}\text { P } \\
\text { Value }\end{array}$ \\
$\begin{array}{c}\text { Axial Length } \\
\text { Endothelial Cell Count } \\
\text { Central Corneal } \\
\text { Thickness }\end{array}$ & 24.79 & 1.03 & 40 & - & - \\
\hline $\begin{array}{c}\text { Table 6. Correlation between Axial Length, Endothelial Cell Count and } \\
\text { Central Corneal Thickness in Axial Myopia Group } \\
\text { Pearson's Correlation Coefficient }\end{array}$ & \\
\\
$\quad$
\end{tabular}

In this study, the mean endothelial cell count in axial myopia group was $2653 \pm 53.91$. The mean endothelial cell count in emmetropia group was $2812 \pm 52.02$

The difference between the two is statiscally significant and thus can be said that corneal endothelial cell count is statiscally lower in axial myopi patients as compared to emmetropic subjects

The mean central corneal thickness in axial myopia group was $489.37 \pm 24.47$.

The mean central corneal thickness in emmetropic group was $490.05 \pm 13.21$. The difference between the two is statistically insignificant, therefore, central corneal thickness is less in axial myopic patients, but statement cannot be made as the difference is not statistically significant.

In axial myopia group, the correlation between axial length and corneal endothelial cell count was statistically significant with $\mathrm{p}$-value $=0.0001$. The correlation between axial length and central corneal thickness was statistically insignificant with $\mathrm{p}$-value $=0.346$. The correlation between axial length and hexagonality was statistically significant with p-value $=0.0001$.

\section{DISCUSSION}

Corneal endothelial cell density and central corneal thickness (CCT) are important parameters for evaluating the cornea. Central Corneal Thickness (CCT), one of the most important corneal parameters, plays an important role in planning various intraocular procedures, refractive surgeries, corneal transplantation etc.

It is $540 \mu \mathrm{m}$ thick centrally on average, and thicker towards the periphery. Central corneal thickness varies between Individuals.

Table 1 shows the agewise distribution of the subjects in both the groups. While there is no relation between the incidence of axial myopia and age as such, maximum number of subjects were $n$ the age group of $25-44$ years whereas maximum number of subjects in emmetropia group were between 35 - 44 years.

Table 2 shows that Out of 20 patients of axial myopia patients, $60 \%$ were males and $40 \%$ were females and out of 20 patients of emmetropia $45 \%$ patients were males and 55 $\%$ were females. This shows that incidence of axial myopia is more in males as compared to females.

Table 3 shows the mean axial length in both the groups.

The mean axial length in axial myopia group was 24.79 $\mathrm{mm}$ with standard deviation of $1.03 \mathrm{~mm}$ which is considered to be above normal, hence signifies the elongation of eyeball in axial myopia patients.

While the mean axial length in emmetropia group was $22.39 \mathrm{~mm}$ with standard deviation of $0.47 \mathrm{~mm}$ which is between the considered normal range of $22-24 \mathrm{~mm}$.

Elongation of eyeball results in scleral thinning and thus corneal parameter variations in subjects with raised axial length. ${ }^{7}$

Table 4 shows the correlation of axial length with corneal endothelial cell count in emmetropic subjects and axial myopic subjects.

The mean corneal endothelial cell count in axial myopia group was 2653 cells $/ \mathrm{mm}^{2}$ with standard deviation of 340.99 cells $/ \mathrm{mm}^{2}$ and the man corneal endothelial cell count in emmetropia group was 2812.80 cells $/ \mathrm{mm}^{2}$ with standard deviation of 329.005 cells $/ \mathrm{mm}^{2}$.

The difference between the corneal endothelial cell count in the two groups was calculated with students unpaired ttest and $\mathrm{p}$ value came to be 0.036 which indicated the statistical difference, therefore based on the observation we can say that there is a statistical difference in the corneal endothelial cell count between emmetropia and axial myopia subjects.

Shu-Wen Chang et al conducted the study on the cornea of young myopic patients and concluded that there was decreased endothelial cell density in myopic patients which was significantly lesser in myopes. ${ }^{8}$

Delshad $\mathrm{S}$ et al concluded in a study that corneal endothelial cell density was lesser in moderate myopic patients than low myopic patients. ${ }^{9}$

Kumiko Kato et al conducted a study on refractive errors and biometrics of the anterior segment of eye which 
concluded that, the correlation between the refractive error and the corneal endothelial cell density was not significant, however there was no data found in relation to the axial length and corneal endothelial cell count. ${ }^{7}$

Table 5 shows the correlation between the central corneal thickness in the emmetropia group and axial myopia group.

The mean central corneal thickness in the axial myopia group was 489.37 micrometers with standard deviation of 24.47 micrometers, while the mean central corneal thickness in emmetropia group was 490.05 micrometers with standard deviation of 13.21 micrometers. Student's unpaired t-test was performed, and p-value came to be 0.87 . Therefore, we can say that there is no statistically significance difference in the central corneal thickness in emmetropia and axial myopia group of subjects.

In a study conducted by Mostafa A et al in January 2018, it was concluded that there was no difference in Central Corneal Thickness between emmetropic and myopic eyes. ${ }^{10}$

Central Corneal Thickness did not correlate with the degree of myopia. The only difference being, that pachymetry was used in this study whereas, we used specular microscopy for calculating central corneal thickness.

Kumiko Kato et $\mathrm{al}^{7}$ conducted a study on refractive errors and biometrics of the anterior segment of eye which concluded that, the correlation between the refractive error and the central corneal thickness was statistically significant, and there was no data found in relation to the axial length and central corneal thickness.

In a study conducted by Yasir Kadhim et al, it was invariably seen that no significant difference was found when each of the myopia subclassifications and emmetropia was done. ${ }^{11}$ In a study conducted by Hani.S et al ${ }^{12}$ it was seen that the CCT of myopic and emmetropic eyes did not differ significantly. In addition, there was no correlation between CCT and the level of myopia.

In another original article, while comparing the Central Corneal Thickness in myopes, hyperopes and emmetropes of different age groups, no statistical significance was found and no variation in CCT was seen as age progressed. ${ }^{13}$

Table 6 shows the correlation of axial length with corneal endothelial cell count, correlation of axial length with central corneal thickness and correlation of axial length. And it showed that there was a statistically significant positive correlation between axial length ${ }^{14,15}$ and corneal endothelial cell count within the axial myopia group.

The correlation between the axial length and central corneal thickness was not statistically significant within the axial myopia group.

This study helps us determine that there is no correlation of axial length with any of the 3 parameters that are studied when axial length is within the normal range of $22-24 \mathrm{~mm}$, but as the axial length increases more than $24 \mathrm{~mm}$ the corneal endothelial cell count and hexagonality have significant correlation with the increasing axial length whereas the central corneal thickness have none.

\section{CONCLUSIONS}

This is a prospective comparative study, which was conducted at a tertiary care center and it showed that the corneal endothelial cell count was significantly decreased in the axial myopia group subjects as compared to the emmetropia group subjects. It also showed that the central corneal thickness and hexagonality was less in the axial myopia group subjects as compared to emmetropia group subjects, but it was not statistically significant. Hence, we can conclude that corneal endothelial cell count is inversely proportional to the axial length of the subject whereas no significant correlation was found in the central corneal thickness and percentage hexagonality between emmetropia and axial myopia subjects.

\section{Limitations}

- Sample size for this study is relatively small.

- Corneal endothelial cell morphology is not considered in the study which is as important as corneal endothelial cell density.

- Ultrasound pachymetry is more accurate and gold standard measurement of central corneal thickness rather than specular microscopy.

- Bias - There could have been a difference in A-SCAN which is eliminated by assigning a single technician and single method for the measurement of the axial length.

\section{Future Prospects}

As the age group taken is $15-49$ years, it is the most productive age group in terms of nation's economy and accounts for more than half of India's population. Confocal microscopy can be used for more advanced studies.

Data sharing statement provided by the authors is available with the full text of this article at jemds.com.

Financial or other competing interests: None.

Disclosure forms provided by the authors are available with the full text of this article at jemds.com.

\section{REFERENCES}

[1] Hou W, Norton TT, Hyman L, et al. Axial elongation in myopic children and its association with myopia progression in the correction of myopia evaluation trial. Eye Contact Lens 2018;44(4):248-59.

[2] Patkar P, Sune P. Evaluation of tear film functions preoperatively and postoperatively in cases with pterygium: a case control study. J Clin Diagn Res 2020;14(1):NC10-3.

[3] Shende V, Iratwar S, Daigavane S. Ocular manifestations in patients with intracranial space-occupying lesions. J Datta Meghe Inst Med Sci Univ 2019;14(3):119.

[4] Mukherji R, Sune P. Contrast sensitivity and visual acuity before and after Nd: YAG capsulotomy in patients with posterior capsular opacification: a prospective study. J Clin Diagn Res 2020;14(3):NC05-8.

[5] Beg S, Lohiya S. Prevalence of refractive errors and colour blindness in school going children of wardha tehsil: a prospective study. J Clin Diagn Res 2020;14(3):NC01-4.

[6] Kalode V, Daigavane S. Study of visual outcome and complications of iris-claw intraocular lens implantation 
to correct aphakia. J Datta Meghe Inst Med Sci Univ 2019;14:141-54.

[7] Kato K, Kondo M, Takeuchi M, et al. Refractive error and biometrics of anterior segment of eyes of healthy young university students in Japan. Scientic Rep 2019;9:15337.

[8] Chang SW, Tsai IL, Hu SR, et al. The cornea in young myopic adults. Br J Ophthalmol 2001;85(8):916-20.

[9] Delshad S, Chun JM. Corneal endothelial cell density and morphology in low and moderate myopic Chinese eyes. Int J Ophthalmol 2013;6(4):46-70.

[10] Mostafa A, Mohammed M. Correlation between central corneal thickness and degree of myopia. Egyptian J Hospital Med 2018;70(1):109-13.

[11] Kadhim YJ, Farhood QK. Central corneal thickness of Iraqi population in relation to age, gender, refractive errors and corneal curvature: a hospital-based cross- sectional study. Clin Ophthalmol (Auckland, N.Z.), 2016;10:2369-76.

[12] Al-Mezaine HS, Al-Obeidan S, Kangave D, et al. The relationship between central corneal thickness and degree of myopia among Saudi adults. Int Ophthalmol 2009;29(5):373-78.

[13] Kalikivayi L, Ratheesan K, Kalikivayi V. Comparison of central corneal thickness in myopes, hyperopes and emmetropes of different age groups. J Clin Ophthalmol 2018;2(2):96-100.

[14] Mourad MS, Rayhan RA, Moustafa M, et al. Correlation between central corneal thickness and axial errors of refraction. J Egypt Ophthalmol Soc 2019;112(2):52-60.

[15] Elijah CN, Pedro ECN, Ejimadu CS. Association between myopia and central corneal thickness among patients in a tertiary hospital in South-South Nigeria. Adv Ophthalmol Vis Syst 2016;5(2):221-3. 